\title{
Análise descritiva por ordenação na caracterização sensorial de iogurte diet sabor morango enriquecido com concentrado protéico do soro
}

\author{
Ranking descriptive analysis in the sensory characterization \\ of strawberry flavored diet yogurt enriched with whey protein \\ concentrate
}

\author{
Milene Moreira Ribeiro Loures ${ }^{1}$; Valéria Paula Rodrigues Minim²*; \\ Elaine Berger Ceresino ${ }^{3}$; Renata Carolina Carneiro ${ }^{4}$; Luis Antonio Minim ${ }^{5}$
}

\section{Resumo}

\begin{abstract}
Este estudo avaliou as características sensoriais de iogurte diet sabor morango enriquecidos com concentrado protéico de soro (CPS). Três formulações contendo $0,5 \%, 1 \%$ e $1,5 \%$ de CPS (F2, F3 e F4 em ordem crescente de concentração) e uma formulação controle sem adição de CPS (F1) foram desenvolvidas e avaliadas por meio da Análise Descritiva por Ordenação. Vinte provadores selecionados e treinados avaliaram as amostras caracterizadas pelos atributos: cor rosa, viscosidade, aroma característico de iogurte de morango, sabor característico de iogurte de morango, gosto doce, gosto ácido e consistência. As formulações diferiram significativamente $(p<0.05)$ nos atributos gosto doce e consistência. As amostras F3 e F4 apresentaram maior consistência confirmando a eficiência do CPS no aumento da consistência.
\end{abstract}

Palavras-chave: Iogurte diet, características sensoriais, concentrado protéico de soro

\begin{abstract}
This study evaluated the sensory characteristics of diet strawberry flavored yogurt enriched with whey protein concentrate (WPC). Three formulations containing $0,5 \%, 1 \%$ and $1.5 \%$ of WPC (F2, F3 and F4 in order of increasing concentration) and a controlled formulation without the addition of WCP (F1) were developed and evaluated by Ranking Descriptive Analysis. Twenty selected and trained panelists evaluated the samples characterized by attributes: pink color, viscosity, characteristic aroma of strawberry yogurt, characteristic flavor of strawberry yogurt, sweet taste, sour taste and consistency. The formulations differed significantly $(\mathrm{p}<0.05)$ in the attributes sweet taste and consistency. Samples F3 and F4 showed greater consistency confirming the efficiency of the WPC in increasing the consistency.
\end{abstract}

Key words: Diet yogurt, sensory characteristics, whey protein concentrate

\footnotetext{
${ }^{1}$ Mestrado em Ciência e Tecnologia de Alimentos, Universidade Federal de Viçosa - UFV. E-mail: milene.ribeiro@gmail.com

2 Doutorado em Ciência de Alimentos (UNICAMP), Professora do Departamento de Tecnologia de Alimentos - DTA, Endereço: Departamento de Tecnologia de Alimentos, Campus Universitário - UFV, Viçosa/MG, CEP 36570-000; E-mail: vprm@ufv.br

${ }^{3}$ Graduanda em Engenharia de Alimentos, Universidade Federal de Viçosa - UFV. E-mail: elaineceresino@gmail.com

${ }^{4}$ Graduanda em Engenharia de Alimentos, Universidade Federal de Viçosa - UFV. E-mail: natycaroline@yahoo.com.br

${ }^{5}$ Doutorado em Engenharia Química (UNICAMP), Professor do DTA - Universidade Federal de Viçosa - UFV. E-mail: 1minim@ ufv.br

* Autor para correspondência
} 


\section{Introdução}

No Brasil, o consumo de iogurte cresceu consideravelmente nos últimos anos, aumentando 3,5\% em 2007 (NIELSEN, 2008). Assim como o iogurte, a demanda por produtos light e diet tem crescido muito e tende a crescer ainda mais. Nos últimos dez anos, o mercado de alimentos light e diet aumentou 870\%, segundo a Associação Brasileira da Indústria de Alimentos Dietéticos e para Fins Especiais (ABIAD, 2007). As palavras diet e light não são mais associadas apenas às pessoas que têm problemas de saúde ou querem perder peso, mas também aos consumidores que prezam por um corpo saudável e em boa forma. Conforme a ABIAD (2007), é assim com o segmento de bebidas lácteas de baixa caloria, principalmente os iogurtes. Apesar do aumento na demanda por produtos desta categoria, é preciso que as empresas estejam preparadas para conquistar este público.

Para atender aos anseios dos consumidores se faz necessário o desenvolvimento de produtos diet/light com características sensoriais similares às do produto tradicional. A quantidade de sólidos totais no leite, incluindo a gordura, é um fator determinante nas propriedades físicas do iogurte (TAMIME; ROBINSON, 1999). Desta forma, a adição de Concentrado Protéico de Soro (CPS) no leite desnatado, tem se mostrado interessante para melhorar a textura do iogurte, além de possuir um apelo nutricional uma vez que apresenta elevada concentração de proteínas do soro, de alto valor biológico. $\mathrm{O}$ uso destas proteínas como ingredientes em alimentos funcionais lácteos e não-lácteos está aumentando progressivamente devido às suas propriedades nutricionais e funcionais, tais como emulsificação, geleificação, aumento de viscosidade, espumabilidade, entre outras (MACHADO, 2005; MILK INGREDIENTS, 2002).

A qualidade de um alimento implica, entre outras coisas, na satisfação do consumidor. Para o consumidor um produto deve, além de possuir excelentes características físicas, químicas e microbiológicas, apresentar características sensoriais que atendam às suas necessidades e anseios (MINIM, 2006).

A qualidade sensorial de um produto pode ser avaliada por meio de métodos sensoriais descritivos. Estes métodos têm como objetivo descrever as propriedades sensoriais do alimento, proporcionando informações sobre sua aparência, aroma, sabor e textura. O conhecimento das propriedades sensoriais de produtos pode ser um diferencial durante o desenvolvimento e a melhoria de produtos. Conhecendo as propriedades sensoriais é possível trabalhar o método de processamento, a proporção dos ingredientes e os ingredientes utilizados na fabricação do produto a fim de se obter um alimento com perfil sensorial que proporcione melhor aceitação pelo mercado consumidor.

Em 2006, a Análise Descritiva por Ordenação (ADO) foi proposta por Richter (2006). A ADO é uma técnica que descreve as sensações percebidas no produto e ordena as amostras de acordo com a intensidade de cada atributo. Esta metodologia apresenta menor flexibilidade para o provador, que diante da ordenação tem que, necessariamente, separar as amostras, mesmo que estas apresentem intensidades semelhantes em relação a um atributo sensorial. Neste caso, as semelhanças entre as amostras relativas ao perfil sensorial serão observadas na análise dos resultados, mas durante as avaliações a ordenação de produtos semelhantes pode confundir o provador. Apesar de apresentar essa desvantagem, ADO é uma técnica descritiva simples e rápida, que permite pontuar as amostras de acordo com cada atributo (RICHTER, 2006).

A avaliação das propriedades sensoriais de novos produtos é extremamente importante, uma vez que possibilita identificar como as variáveis do produto, no caso deste estudo a concentração do ingrediente CPS, afetam as suas características sensoriais do mesmo. Assim, este trabalho teve como objetivos desenvolver diferentes formulações de iogurte diet sabor morango contendo diferentes concentrações do 
CPS e avaliar o perfil sensorial dessas formulações por meio da ADO.

\section{Material e Métodos}

\section{Processamento do iogurte sabor morango}

Foram realizados testes preliminares a fim de definir um intervalo de concentração de CPS na formulação de tal forma que apresentassem características sensoriais próprias do iogurte, similares aoiogurte tradicional. Foram desenvolvidas quatro formulações de iogurte diet, sendo três com adição de CPS (F2, F3 e F4 contendo 0,5\%, 1,0\% e $1,5 \%$ de CPS respectivamente) e uma controle (F1) sem adição de CPS. Os testes preliminares foram realizados em laboratório em cubas com capacidade para 2L, em estufa B.O.D. com temperatura controlada a $42^{\circ} \mathrm{C}$ durante o processo de fermentação.

Após os testes preliminares, as quatro formulações foram processadas em escala-piloto, utilizando-se tanques com capacidade de 40L, divididos em duas repetições.

No processamento dos iogurtes, o leite desnatado foi previamente adicionado do CPS nas concentrações de $0,5 \%, 1,0 \%$ e $1,5 \%$ e sem adição de CPS. A mistura foi tratada termicamente a $83{ }^{\circ} \mathrm{C} / 30 \mathrm{~min}$. Em seguida, o leite foi resfriado até aproximadamente $42{ }^{\circ} \mathrm{C}$ e inoculado com o fermento comercial da marca Christian Hansen, contendo culturas de Lactobacillus delbrueckii subsp. bulgaricus e Streptococcus thermophilus. $A$ fermentação foi realizada por aproximadamente 4,5 horas, até o leite atingir acidez titulável de 0,70 $-0,75$. Após a fermentação, o gel foi resfriado até a temperatura de aproximadamente $37{ }^{\circ} \mathrm{C}$ e em seguida foi realizada a quebra da massa juntamente com a adição de $1 \%$ da polpa de morango maduro sem pedaços (Frutta Viva) e 0,07\% do aspartame (Doce Aroma). O uso do aspartame e a concentração empregada foram sugeridos por Reis (2007) no estudo realizado para avaliar o efeito de diferentes edulcorantes na qualidade sensorial de iogurte sabor morango. Os iogurtes adoçados com aspartame apresentaram perfis de doçura semelhantes ao iogurte tradicional, além de apresentarem maior aceitabilidade pelo consumidor.Todo iogurte produzido foi envasado em embalagens plásticas de $1 \mathrm{~L}$ e armazenado a $5^{\circ} \mathrm{C}$.

\section{Caracterização sensorial do iogurte}

Condições dos testes

As avaliações foram realizadas no Laboratório de Análise Sensorial do Departamento de Tecnologia de Alimentos da Universidade Federal de Viçosa. Todas as avaliações foram realizadas em cabines individuais, sendo utilizada luz branca para avaliação da aparência e luz vermelha para avaliação do aroma, sabor e textura. As etapas de levantamento dos atributos e de treinamento, nas quais são utilizadas discussões abertas, foram realizadas em mesa redonda.

As amostras avaliadas (F1 sem adição de CPS, F2, F3 e F4 contendo 0,5\%, 1,0\% e 1,5\% de CPS respectivamente), foram apresentadas em copos descartáveis de $50 \mathrm{~mL}$, codificados com números de três dígitos para avaliação dos atributos de aroma, de sabor e de textura, e em béquer de vidro de 200 $\mathrm{mL}$, contendo $125 \mathrm{~mL}$ de amostra, para avaliação dos atributos de aparência. As amostras foram servidas à temperatura de refrigeração $\left(10^{\circ} \mathrm{C}\right)$ em todos os testes.

\section{Recrutamento e pré-seleção de provadores}

Foram distribuídos 50 questionários de recrutamento às pessoas que demonstraram interesse em participar das análises sensoriais descritivas, sendo recrutados para a realização da pré-seleção aqueles que apresentaram disponibilidade de tempo, afinidade pelo produto, habilidade em trabalhar com escala não-estruturada, conhecimento sobre termos descritivos e condições de saúde que não comprometessem as análises. 
A etapa de pré-seleção foi realizada utilizando a amostra F4 e esta diluída com 10\% de leite desnatado da marca Viçosa (F4D). Para utilizar estas amostras nesta etapa foi necessário constatar se as formulações F4 e F4D eram estatisticamente diferentes. Para isto, foi realizado o teste triangular com 20 provadores. Verificou-se pelo teste que as formulações diferiram entre si ao nível de 4\% de probabilidade. Então, as amostras F4 e F4D foram utilizadas para verificar o desempenho dos candidatos a provadores. Na préseleção de provadores foram empregadas quatro repetições do teste triangular, sendo selecionados os candidatos que obtiveram no mínimo duas respostas corretas. Este percentual mínimo de acertos para seleção de provadores atende a recomendação de Neilgard, Civille e Carr (1988), que é de 40\%.

Levantamento dos termos descritivos e treinamento dos provadores

O desenvolvimento da terminologia descritiva foi realizado pelos provadores pré-selecionados em discussão aberta com auxílio da lista prévia de termos descritivos para iogurte obtidos em trabalhos realizados por Reis (2007), Cayot et al. (2008),
Janhoj, Frost e Ipsen (2007), Kip, Meyer e Jellema (2006) e Moraes (2004).

As quatro amostras foram apresentadas juntamente com a lista prévia e então, foi solicitado aos provadores que confeccionassem a lista com os termos descritivos que caracterizassem as amostras apresentadas. Após o levantamento dos atributos os provadores realizaram a definição de cada termo.

Neste estudo, a etapa de familiarização com as amostras realizada no estudo de Richter (2006) foi substituída por uma sessão de treinamento com os termos descritivos característicos do iogurte e seus respectivos padrões. Cada provador passou por uma sessão de treinamento na qual foram apresentados os padrões, juntamente com a lista de definição para cada atributo.

\section{Avaliação das amostras e análise dos resultados}

A avaliação das amostras foi realizada em uma única sessão, por vinte provadores, empregando-se a ficha de avaliação (Figura 1).

Os dados coletados referentes a todos os atributos foram avaliados por meio do teste de Friedman, ao nível de 5\% de probabilidade (CHAVES, 2001).

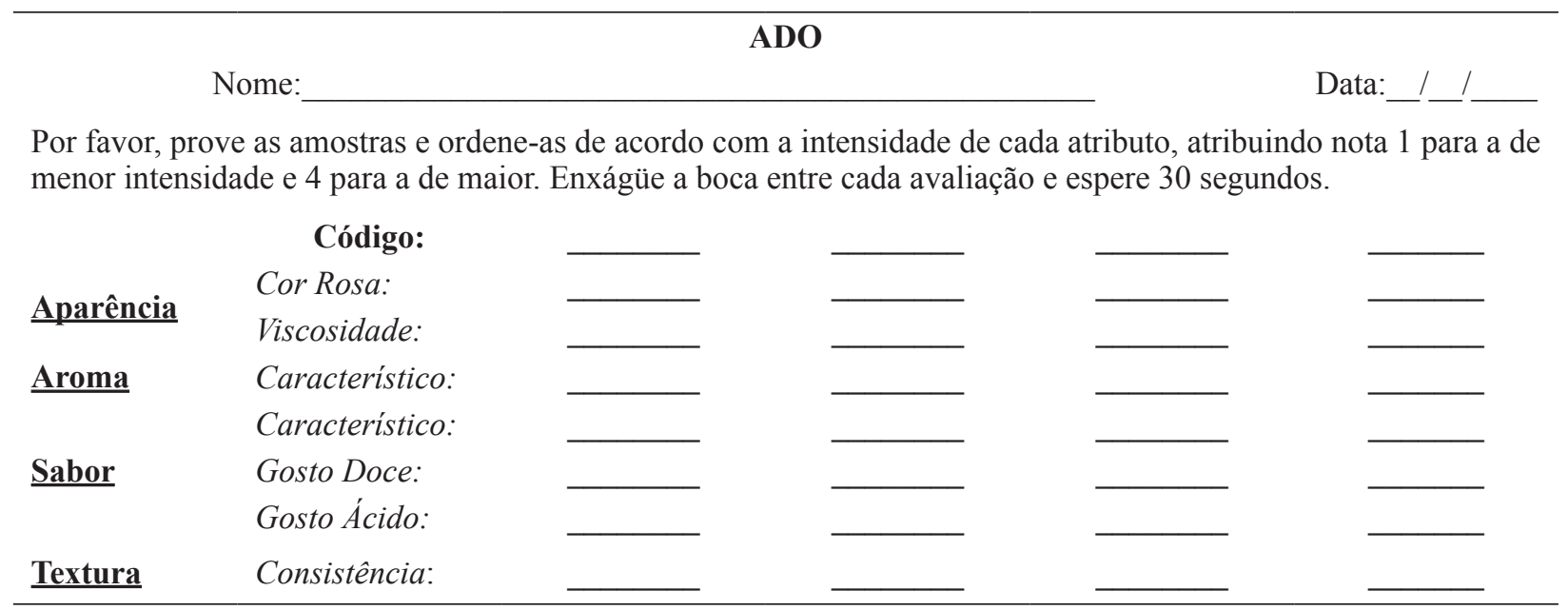

Figura 1. Ficha da ADO empregada na avaliação das amostras de iogurte diet sabor morango enriquecido com CPS. 


\section{Resultados e Discussão}

\section{Recrutamento e pré-seleção dos provadores}

Foram distribuídos 50 questionários, sendo recrutados 33 voluntários para participarem da equipe sensorial. Destes, 20 acertaram pelo menos $50 \%$ dos testes triangulares e foram pré-selecionados, sendo 15 mulheres e 5 homens. Os provadores préselecionados participaram do levantamento dos termos descritivos para as amostras de iogurte diet sabor morango.

\section{Levantamento dos termos descritivos}

No levantamento dos termos descritivos sete termos foram selecionados pela equipe como sendo os que melhor caracterizavam as amostras de iogurte. Os atributos levantados para avaliação dos iogurtes diet sabor morango foram: cor rosa, viscosidade, aroma característico, sabor característico, gosto doce, gosto ácido e consistência (Tabela 1).

Tabela 1. Atributos, definições e padrões de referência para o iogurte diet sabor morango

\begin{tabular}{lll}
\hline Atributos & Definições & Padrões \\
\hline \multirow{3}{*}{ Cor Rosa } & $\begin{array}{l}\text { Cor rosa característica } \\
\text { iogurte de morango. }\end{array}$ & $\begin{array}{l}\text { Clara: Iogurte natural da marca Nestlé adicionado de 1\% de polpa } \\
\text { de morango. } \\
\text { Escura: Iogurte de morango da formulação F1 adicionado de 1\% } \\
\text { de polpa de morango. }\end{array}$ \\
\hline
\end{tabular}

Propriedade de resistência

Viscosidade ao escoamento em recipiente de vidro.
Fraco: Iogurte de morango da formulação F1 diluído com leite pasteurizado desnatado da marca Viçosa na proporção 1:1

Forte: Iogurte de morango formulado com leite desnatado adicionado de $5 \%$ de CPS

\begin{tabular}{ll}
$\begin{array}{l}\text { Sabor } \\
\text { Característico } \\
\text { de Iogurte de } \\
\text { Morango }\end{array}$ & $\begin{array}{l}\text { Sabor característico de } \\
\text { substâncias voláteis da fruta } \\
\text { morango e produtos da } \\
\text { fermentação do iogurte. }\end{array}$ \\
\hline Gosto Doce & $\begin{array}{l}\text { Gosto percebido pela mucosa } \\
\text { oral semelhante aquele } \\
\text { provocado pela sacarose. }\end{array}$
\end{tabular}

Fraco: Iogurte de morango da formulação F3 diluído com leite pasteurizado desnatado da marca Viçosa na proporção 1:1

Forte: Iogurte de morango da formulação F3 adicionado de $2 \%$ de polpa de morango.

Nenhum: Iogurte natural da marca Nestlé adicionado de $1 \%$ de polpa de morango.

Forte: Iogurte de morango da formulação F2 adicionado de 0,1 \% de aspartame

Gosto percebido pela mucosa oral provocado pelos íons

Gosto Ácido $\mathrm{H}^{+}$. Gosto associado ao ácido lático, característico da fermentação do iogurte.

Fraco: Iogurte de morango da formulação F1 diluído com leite pasteurizado desnatado da marca Viçosa na proporção 1:1

Forte: Iogurte de morango da formulação F3 com acidez titulável de 0,89 no momento da quebra da massa.

\begin{tabular}{|c|c|c|}
\hline o & $\begin{array}{l}\text { roma caracterí } \\
\text { abstâncias voláte } \\
\text { lorango e pro } \\
\text { rmentação do io }\end{array}$ & $\begin{array}{l}\text { pa } \\
\text { Fo }\end{array}$ \\
\hline
\end{tabular}

Representa a espessura do alimento na boca depois do mesmo ter sido comprimido para cima e para baixo por movimento da língua contra o palato.
Fraco: Iogurte de morango da formulação F1 diluído com leite pasteurizado desnatado da marca Viçosa na proporção 1:1

Forte: Iogurte de morango formulado com leite desnatado adicionado de $5 \%$ de CPS 
As formulações diferiram significativamente ( $\mathrm{p}$ $\leq 0,05$ ) entre si nos atributos consistência e gosto doce.

As formulações com $0,5 \%$ e sem adição de CPS diferiram das formulações contendo $1,0 \%$ e $1,5 \%$ de CPS em relação à consistência pelo teste de Friedman ao nível de 5\% de probabilidade, sendo as formulações com maior concentração de CPS as mais consistentes. Quanto ao gosto doce, as formulações F1 e F2 diferiram da formulação F3, sendo mais doces que F3. A formulação com 1,0\% de CPS apresentou maior intensidade do gosto doce que a amostra enriquecida com $1,5 \%(\mathrm{p} \leq 0,05)$ pelo teste de Friedman (Tabela 2).

Tabela 2. Somas das ordens dos atributos sensoriais para cada amostra de iogurte diet sabor morango com diferentes concentrações de CPS.

\begin{tabular}{|c|c|c|c|c|}
\hline \multirow[b]{2}{*}{ ATRIBUTOS } & \multicolumn{4}{|c|}{ Formulação } \\
\hline & $\begin{array}{c}\text { Controle } \\
\text { (F1) }\end{array}$ & $\begin{array}{c}0,5 \% \text { CPS } \\
\text { (F2) }\end{array}$ & $\begin{array}{c}1,0 \% \text { CPS } \\
\text { (F3) }\end{array}$ & $\begin{array}{c}1,5 \% \text { CPS } \\
\text { (F4) }\end{array}$ \\
\hline \multicolumn{5}{|l|}{ APARÊNCIA } \\
\hline Cor Rosa & $53 \mathrm{a}$ & $56 a$ & $37 \mathrm{a}$ & $54 \mathrm{a}$ \\
\hline Viscosidade & $49 \mathrm{a}$ & $39 \mathrm{a}$ & $55 \mathrm{a}$ & $57 \mathrm{a}$ \\
\hline \multicolumn{5}{|l|}{ AROMA } \\
\hline Aroma Característico & $46 \mathrm{a}$ & $44 \mathrm{a}$ & $52 \mathrm{a}$ & $58 \mathrm{a}$ \\
\hline \multicolumn{5}{|l|}{ SABOR } \\
\hline Sabor Característico & $49 \mathrm{a}$ & $53 \mathrm{a}$ & $41 \mathrm{a}$ & $57 \mathrm{a}$ \\
\hline Gosto Doce & $57 \mathrm{a}, \mathrm{b}$ & $65 \mathrm{a}$ & $33 \mathrm{c}$ & $46 \mathrm{~b}, \mathrm{c}$ \\
\hline Gosto Ácido & $42 \mathrm{a}$ & $41 \mathrm{a}$ & $60 \mathrm{a}$ & $57 \mathrm{a}$ \\
\hline \multicolumn{5}{|l|}{ TEXTURA } \\
\hline Consistência & $37 \mathrm{~b}$ & $38 \mathrm{~b}$ & $64 \mathrm{a}$ & $61 \mathrm{a}$ \\
\hline
\end{tabular}

Valores seguidos de uma mesma letra, numa mesma linha, não diferem entre si pelo teste de Friedman ao nível de $5 \%$ de probabilidade.

O processamento das formulações foi realizado da mesma forma, sendo todas as etapas padronizadas. Quanto aos ingredientes, as formulações diferiam entre si somente pela concentração de CPS. O gosto doce, apesar de todas as formulações apresentarem a mesma concentração de aspartame, diferiu entre as amostras. É possível que a percepção do gosto doce tenha sido alterada devido às diferenças na consistência dos iogurtes. Hewson et al. (2008) investigaram a interação entre os atributos sensoriais em bebidas cítricas e os resultados apontaram interação significativa entre viscosidade e gosto doce. Segundo Hewson et al. (2008) o aumento na viscosidade diminui a percepção da doçura, o que explica a diferença entre as amostras quanto ao gosto doce.
A consistência aumentou nas formulações que continham mais concentrado protéico de soro (CPS). Isto demonstra que o CPS foi importante na composição da textura do iogurte.

Os resultados obtidos estão coerentes com os encontrados por Antunes, Mota e Antunes (2003) e Isleten e Karagul-Yuceer (2006). Os resultados obtidos por Antunes, Mota eAntunes (2003) apontam um aumento na firmeza dos géis de CPS com o aumento no teor de concentrado protéico utilizado. Isleten e Karagul-Yuceer (2006) investigaram a fortificação de iogurte com isolado protéico do soro e o acréscimo das proteínas favoreceu o aumento da viscosidade e da consistência do produto. 


\section{Conclusão}

Com a utilização da metodologia ADO foi possível caracterizar sensorialmente as amostras estudadas de maneira eficiente. Como esta metodologia possui menor número de etapas, foi possível obter resultados de maneira rápida e econômica, uma vez que a redução de etapas na metodologia implica na menor utilização de amostras. Vale lembrar, que apesar da facilidade e rapidez do método, os resultados apenas descrevem as amostras e as diferenciam sem quantificar cada atributo e por isto, não pode ser empregada em todas as situações como substituta de metodologias como a Análise Descritiva Quantitativa.

\section{Agradecimentos}

Ao CNPq e à FAPEMIG, pelo apoio financeiro.

\section{Referências}

ABIAD. Associação brasileira das indústrias de alimentos dietéticos e para fins especiais. Disponível em: <http://www.abiad.org.br $>$. Acesso em: 13 ago. 2007.

ANTUNES, A. E. C.; MOTTA, E. M. P.; ANTUNES, A. J. Perfil de Textura e Capacidade de Retenção de Água de Géis Ácidos de Concentrado Protéico de Soro de Leite. Ciência e Tecnologia de Alimentos, Campinas, v. 23, p. 183-189. 2003. Suplemento.

CAYOT, P.; SCHENKER, F.; HOUZÉ, G.; SULMONTROSSÉ, C.; COLAS, B. Creaminess in Relation to Consistency and Particle Size in Stirred Fat-Free Yoghurt. International Dairy Journal, Kidlington, v. 18, n. 3, p. 303-311, 2008.

CHAVES, J. B. P. Métodos de diferença em avaliação sensorial de alimentos e bebidas. Viçosa, MG: UFV, $2001.91 \mathrm{p}$.

HEWSON, L.; HOLLOWOOD, T.; CHANDRA, S.; HORT, J. Taste-aroma interactions in a citrus flavoured model beverage system: Similarities and differences between acid and sugar type. Food Quality and Preference, v. 19, n. 3, p. 323-334, 2008.

ISLETEN, M.; KARAGUL-YUCCER, Y. Effects of dried dairy ingredients on physical and sensory properties of nonfat yogurt. Journal of Dairy Science, Lancaster, v. 89, n. 8, p. 2865-2872, 2006.

JANHOJ, T.; FROST, M. B.; IPSEN, R. Sensory and rheological characterization of acidified milk drinks. Food Hydrocolloids, Oxford, v. 22, n. 5, p. 798-806, 2008.

KIP, P.; MEYER, D.; JELLEMA, R. H. Inulins improve sensoric and textural properties of low-fat yoghurts. International Dairy Journal, Kidlington, v. 16, n.9, p. 1098-1103, 2006.

MACHADO, G. C. Utilização de óleo de coco de babaçu, concentrado protéico do soro lácteo e leite em pó desnatado na produção de sorvetes. Tese (Doutorado em Ciências e Tecnologia de Alimentos) - Departamento de Tecnologia de Alimentos. Universidade Federal de Viçosa. Viçosa, MG, 2005.

MILK INGREDIENTS. Whey protein concentrate. 2002. Disponível em: <http://www.milkingredients.ca> Acesso em: 20 mar. 2008.

MINIM, V. P. R. Análise sensorial: estudos com consumidores. Viçosa, MG: UFV, 2006. 225 p.

MORAES, P. C. T. B. Avaliação de iogurtes líquidos comerciais sabor morango: estudo de consumidor $e$ perfil sensorial. Dissertação (Mestrado em Alimentos e Nutrição) - Departamento de Alimentos e Nutrição. Universidade Estadual de Campinas. Campinas, 2004.

NEILGARD, N.; CIVILLE, V.; CARR, B. T. Sensory evaluation techniques. Flórida: CRC PRESS INC. BOCA RATON, 1988. $279 \mathrm{p}$.

NIELSEN. The Nielsen Company. Resultados do consumo no Brasil em 2007. Disponível em: <http:// br.nielsen.com/news/fechamento2007.shtml>. Acesso em: 10 mar. 2008.

REIS, R. C. Iogurte “light” sabor morango: equivalência de doçura, caracterização sensorial e impacto da embalagem na intenção de compra do consumidor. Tese (Doutorado em Ciência e Tecnologia de Alimentos) Departamento de Tecnologia de Alimentos. Universidade Federal de Viçosa. Viçosa, MG, 2007.

RICHTER, V. B. Desenvolvimento de uma técnica descritiva por ordenação. Dissertação (Mestrado em Ciência de Alimentos) - Departamento de Ciência e Tecnologia de Alimentos. Universidade Estadual de Londrina. Londrina, 2006.

TAMIME, A. Y.; ROBINSON, R. K. Yoghurt science and technology. Inglaterra: Ed. Woodhead Publishing Ltd., 1999. $619 \mathrm{p}$. 
